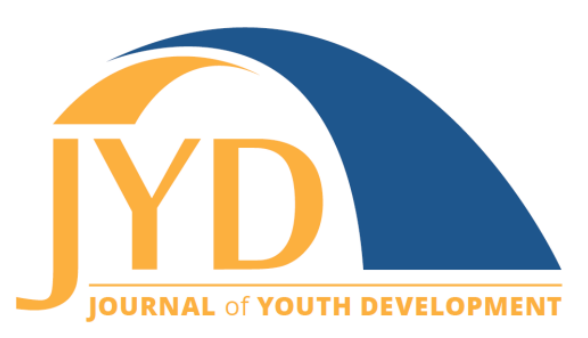

http://jyd. pitt. edu/ | Vol. 14 Issue 2 DOI 10.5195/jyd.2019.717 | ISSN 2325-4017 (online)

\title{
Understanding Youths' Educational Aspirations in the Somali Diaspora
}

\author{
Joanna A. Tzenis \\ University of Minnesota, Extension Center for Youth Development \\ tzeni004@umn.edu
}

\begin{abstract}
This article shares findings from a 10-month qualitative longitudinal study that offer insight into the educational aspirations of American youth (grades 6-9) who belong to the Minnesota Somali diaspora and highlight the social and cultural influences that shape these aspirations. The findings show that while the majority of youth participants (at one point in the study) expressed that they wanted to become doctors in the future, these aspirations were informed by family values around helping others in Somalia-not an interest in medicine or science. The findings also demonstrate that through time, as the high school youth began to engage more deeply in non-diasporic environments, such as school, their aspirations became more open-ended and individualized. Each of the youth in this study was a child of Somali-born parents; they were living and receiving an education in the United States, and their aspirations for the future were imagined and reimagined in these multiple contexts. The importance of these findings is that they demonstrate how youths' cultural ties to Somalia enabled them to aspire. These findings also bring attention to the social and cultural conditions Somali diasporic youth navigate as they strive for a healthy transition into adulthood. It is my hope that the findings from this article will support educators' and youth workers' abilities to respond to and support the positive developmental processes of youth living in the American Somali diaspora by widening the sets of opportunities they have to healthily navigate early adolescence and achieve their aspirations for the future.
\end{abstract}

Key words: youth, adolescence, aspirations, Somali diaspora, qualitative research methods

\section{Introduction}

For youth in the Somali diaspora, education is deeply tied to imaginations for a better future (Bigelow, 2010). A recent student survey showed that youth in Minnesota, who identify as Somali, self-reported a higher commitment to education than any other cultural group in the state (Minnesota Department of Education, 2016). Youth in the Minnesota Somali diaspora also

(c) $\mathrm{EY}_{\mathrm{EY}}$ New articles in this journal are licensed under a Creative Commons Attribution 4.0 License. This journal is published by the University Library System, University of Pittsburgh and is cosponsored by the University of Pittsburgh Press. The Journal of Youth Development is the official peer-reviewed publication of the National Association of Extension 4-H Agents and the National AfterSchool Association. 
Youth Aspirations in the Somali Diaspora

reported high levels of family support, and empirical studies suggest that Somali parents have a positive attitude toward education (e.g. Basford, 2008; Bigelow, 2010). This matters because research also suggests that having a positive attitude toward education-especially one shared by parents and children alike-is correlated with positive educational outcomes (Kapteijns \& Arman, 2008). And yet, educational attainment in the Minnesota Somali diaspora is low. Among Somali adults between the ages 25 and 64 living in Minnesota, 34\% do not have a high school diploma or GED. Only $11 \%$ of adult Minnesotans who identify as Somali have earned at least an associate's degree (Minnesota State Demographic Center, 2016). Among Minnesota high school students, dropout, truancy, and suspension rates remain high in the Somali diaspora (TAYO Consulting Group, 2016). There is a gap between what young people and their families aspire for themselves through education and what they are actually achieving. Because of this disparity, this article investigates aspirations in the Somali diaspora and the role they play in youths' abilities to achieve the life they and their families desire through educational attainment. It is my hope that the findings presented in this article may be helpful to educators, youth workers, and community leaders so that they might find effective ways to support young people in the Somali diaspora along their educational pathways toward valued futures.

\section{Literature Review}

\section{Conceptualizing Aspirations}

This article draws on Appadurai's (2004) conceptualization of aspirations. Appadurai helps us understand that an aspiration is not synonymous with individual motivation and ambition; nor is it a trait that some young people lack and others possess. Rather, it is a cultural capacity, constructed "in the thick of social life" (p. 67) embedded with family-mediated values that shape young people's imaginations for the future. Understanding aspirations in this way redirects educational and youth work practices away from solely trying to instill youth with an individual drive to succeed or with "grit" (e.g., Duckworth, 2016). Instead, it draws attention to the reality that some young people have more opportunities to exercise their capacity to explore pathways to their imagined futures-in part because of the unequal distribution of social and cultural capital (Bok, 2010; Bourdieu \& Passeron, 1990). This article will assess aspirations in the Somali diaspora with this conceptual understanding. In doing so, this article calls attention to the social and cultural assets youth carry with them into their educational settings so that educators and youth work practitioners might consider how to validate these assets. Further, by understanding youths' aspirations as socially and culturally informed (and not individually held), 
Youth Aspirations in the Somali Diaspora

the findings from this study call attention to the multiple (and often discordant) social and cultural contexts in which young people in the Somali diaspora engage.

\section{Aspirations and Positive Youth Development}

It is foundational knowledge in the field that positive youth development happens in multiple spaces: at home, school, neighborhoods, religious organizations, the list goes on (Hirsch, 2005). Each space-each social context-is characterized by values and ways of being and doing that shape behavior, identity formation, and a sense of hope for one's future (Bourdieu, 1990; Zipin, Sellar, Brennan, \& Gale, 2015). Some youth can smoothly transition from home life to school life; other youth experience a mismatch of values, which can complicate their abilities to achieve their aspirations (Zipin et al, 2015).

Studies on the cultural and social resources of immigrant youth (e.g. Bankston \& Zhou, 2002; Stanton-Salazar, 2011; Hurtado, Fife, Svetaz, \& Allen, 2018) demonstrate that navigating discrepant value systems is an enduring challenge among immigrant youth and youth of immigrant parents; it often leads to family stress, lowered educational performance, and general lack of belonging in school. DeJaeghere (2018) points out that culture is often misguidedly identified as the culprit for these strained outcomes, as young people are seen as sticking with traditions that hold them back. Appadurai (2004) helps us understand that culture (which is primarily mediated and upheld through relationships and family networks) is what actually enables youth to have and strive for aspirations. Unfortunately, many youths' cultural capacities to aspire can be constrained because the systems they must navigate in order to achieve their aspirations are located outside of the experience of their primary place of belonging: their family (Bok, 2010; Prodonovich, Perry, \& Taggart, 2014). Studies of social reproduction would further theorize that educational spaces, such as schools, do not value the cultural assets youth bring from their family, and this strains youths' abilities to achieve favorable educational outcomes (Bourdieu \& Passeron, 1990; Reay, 2004). In other words, youths' family-mediated cultural assets are a catalyst to positive change and have the potential to widen youths' sets of educational opportunities, but they must be acknowledged and considered in youths' non-family contexts (DeJaeghere, 2018). Understanding youths' aspirations and the conditions that shape them (i.e. the purpose of this study) will begin to bring these cultural assets to light, laying the groundwork for educators, youth workers, and community members to widen systems of support for youth and families. 
Youth Aspirations in the Somali Diaspora

In the following sections, I show how the aspirations of youth in the Somali diaspora are constructed in social and cultural contexts, how they change over time, and I discuss the role they play in youths' positive development. Before discussing the study's findings, I briefly describe the educational context and the methodology used to understand these youths' educational aspirations.

\section{The Research Study}

\section{The Context: Education in the Minnesota Somali Diaspora}

Minnesota is home to the largest Somali population in North America (Yusuf, 2012). Many youth in the Minnesota diaspora are the children of Somali-born parents who left their homes, families, and their own educational pursuits in Somalia in order to escape a violent civil war that engulfed their homeland for decades (Yusuf, 2012). Family networks, job opportunities, and educational opportunities are all cited as reasons for so many Somali families making Minnesota their home after years in refugee camps (TAYO Reporting Group, 2016). Many Somali-born parents, like the parents in this study, are now raising first-generation American children with the fervent expectation that this next generation will receive an education so that they may improve their own lives and the lives of others (Bigelow, 2010; Tzenis 2018).

While there is evidence that suggests education is deeply esteemed in the Somali community, there are few studies that seek to understand the conditions that shape the educational aspirations of Somali families living in the United States. The majority of the studies on Somali youth identify educational barriers and reasonably attribute the low educational attainment of youth in the Somali diaspora to these barriers youth encounter on account of their identities. For instance, Bigelow (2010) shows how youths' experiences with "xenophobia, racism, and Islamophobia" in school takes its toll on young people, and they "justifiably disengage" from their education (p. 148). Abdi (2015) demonstrates how Somali youth face negative stereotypes (e.g., being viewed as threats or difficult to educate) that can affect youths' sense of belonging and safety in their school environment. This research highlights barriers (and quite conspicuous ones at that) youth in the Somali diaspora face on account of their social identities-barriers that must be removed. This study extends this literature by bringing about deeper understanding of the value youth and families place on receiving an education. I argue that focusing solely on the barriers youth encounter runs the risk of overlooking the assets they contribute. There is a need to better understand the social and cultural values, norms, and 
Youth Aspirations in the Somali Diaspora

ways of being young people in the Somali diaspora bring into their educational settings so that they be valued in an educational setting, be it formal or non-formal.

The few studies that explore the educational experiences of Somali diasporic youth have shown that Somali parents have concerns about their children losing their Somali identity and becoming too "Americanized" by embracing the American individualism pervasive in schools (e.g. Bigelow, 2010; Hussein, 2012). The TAYO Consulting Group, which published a needs assessment report of the Twin Cities Somali community, referred to this as a "crisis of values" $(2016$, p. 18) acknowledging the family tension that occurred when young people in the Somali diaspora embraced values unfamiliar to and disliked by parents. This study explores how this tension takes form in youths' educational aspirations.

\section{Study Participants}

The focal participants for this study were nine first-generation American youth who were participants of two different youth programs, which were designed to serve youth in the Minnesota Somali diaspora and support them on their pathway to higher education. Each young person's parents were born in Somalia, displaced from Somalia on account of the civil war, and spent time in refugee camps before coming to Minnesota. There were six girls and three boys ranging in age from 11 to 15 years (grades 6 through 9). Five youth (four girls, one boy) were members of a youth program located in a suburb with a majority White, middle-class population, and four youth ( 2 girls, two boys) were members of a youth program that took place in an urban neighborhood that was densely populated with Somali families. Also included in this study were five mothers, one father, and one aunt of the focal youth. All youth and family members have been assigned pseudonyms.

\section{Methodology}

This study used qualitative longitudinal research (QLR) methodology to investigate Somali diasporic youths' aspirations and the conditions that influenced them. QLR is particularly useful in capturing the temporality of youths' life stages by using multiple data collection points over an extended period of time (Saldaña, 2003). QLR allowed for flexible understanding of youth, acknowledging that the ways in which young people see themselves and what they believe is possible in their lives might change through time, in different contexts, and in different stages of development (Morrow \& Crivello, 2015). 
Youth Aspirations in the Somali Diaspora

For this article, I analyzed 26 in-depth qualitative interviews from nine youth over a period of 10 months. I interviewed eight of the youth participants at three different points in time. One male participant, temporarily left the program, was not available for a second interview, and was interviewed a two points in time. Multiple data collection points allowed me to understand how aspirations formed and changed over time. I revisited the topic of aspirations at each interview and asked youth to describe changes in their aspirations, if and when change occurred. I also analyzed data from one parent focus group (at the suburban program site) and from field notes with the parents (and one aunt) associated with the urban youth program. At the focus group and in sit-down conversations with me, parents were asked to describe what they wanted for their children's futures. Finally, I led youth in experiential learning activities throughout the study. This method was inspired by the "mapping methods" advocated by Futch and Fine (2014) and intended to take a youth-centered approach to understanding youths' aspirations. This article includes analyzed data from a vision board activity in which youth were prompted to create an image or images that depicted their perfect futures. This method allowed the youth to lead the discussion around their futures while they described their vision board to me and their peers. I analyzed both the verbal (and transcribed) descriptions of their vision boards as well as the vision boards themselves.

\section{Findings}

The presented findings provide evidence supporting three key themes in the data:

1. Most youth aspired to be doctors as a way of acting on family values of helping others.

2. Older youths' aspirations changed through time as they began to more deeply embrace Western values through increased interactions with others outside of their families.

3. Youth cited their parents' support as the primary reason why they held educational aspirations.

\section{"I want to be a doctor" Might Not Mean What You Think.}

At one or more points in the study, seven of the nine participants stated that they wanted to become doctors; the other two said they wanted to enter a science field. In describing why they held these aspirations, youth consistently described ways in which they imagined acting out values their parents instilled in them-primarily the value of helping others-and not an academic interest in the field. 
Youth Aspirations in the Somali Diaspora

Hodan's (grade 6) drawing of her "perfect future" (Figure 1) depicted her working as a doctor in Somalia, a country she has never visited. She said she wanted to be a doctor because "it's fun helping people." When asked why she wanted to work somewhere she had never been, she explained that her family members told her, "there are a lot of patients there" who need help.

\section{Figure 1. Hodan's Perfect Future}

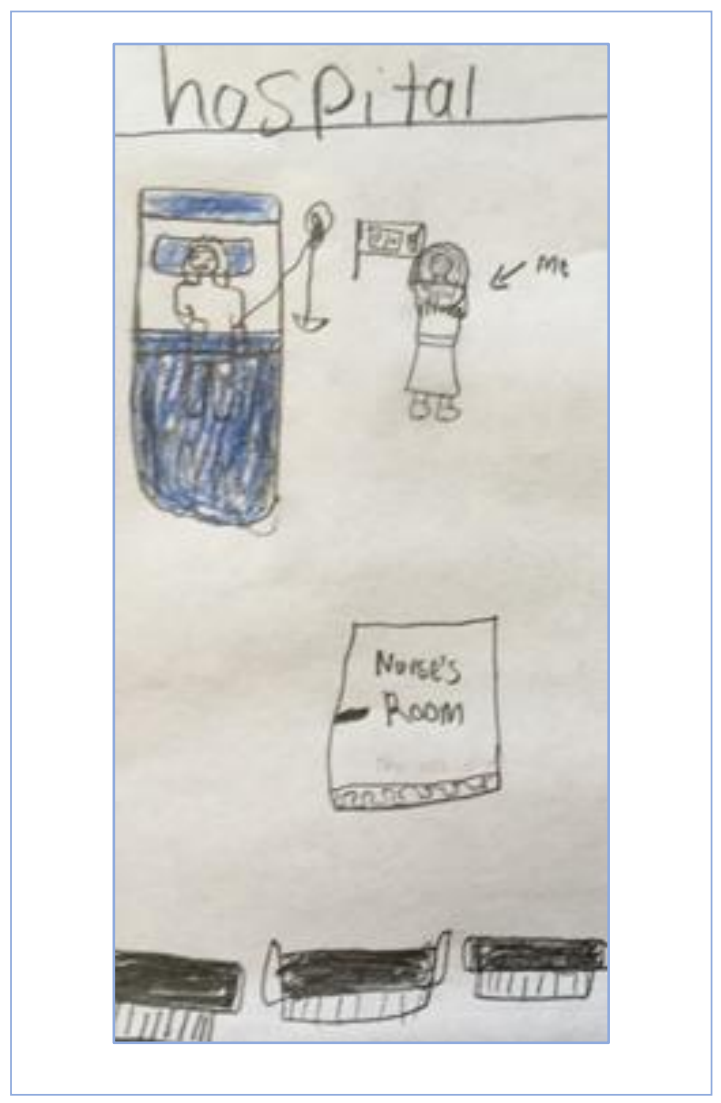

Hamdi, who was in seventh grade and confessed she "hated" science class, explicitly tied her aspirations of being a doctor to her Somali identity and to her desire to "help others." When describing in an interview why her Somali identity was so important to her, she explained:

Because my parents are from there. When I become a doctor I want to go help the less fortunate people that are there. ... It's hard for them because like when my mom was living there, there's a war. . . . They can't afford doctors because they lost all their money. 
Youth Aspirations in the Somali Diaspora

Each of the young people in this study were told stories of the civil war by their parents and shared in interviews that they were encouraged to contribute to the social welfare and renewal of Somalia by becoming educated medical professionals. And while the findings from this study pertain only to the nine youth participants and their families, participants made it clear to me that this was a prevalent value in the Somali diaspora. In fact, the mothers of the suburban club youth participants shared a collective laugh during the focus group when I asked them what they aspired for their children's futures. They treated this presumptive knowledge like an inside joke, but quickly tied their reasoning for their aspirations to helping others in Somalia:

Hibaaq: We are all Somali, we like doctors, engineers. [All laugh.]

We like-I would like [them to] become a doctors or engineers.

Joanna: Why do people who are Somali want those specific

careers for their kids?

Nimo: Because our country we don't have . . enough doctors.

We have a civil war and I always tell my kids, when they speak

more English at home, I tell them, "Speak Somali because when

you becoming a doctor you're going there and help the

community."

Fatima, another mother, who at the time of the study was pursuing her associate's degree in community development, went on to illustrate this point while also emphasizing the value she shared with her children that an education is not a means to individual prosperity, but a social good: "You get the education, you don't want to keep it for yourself. There so many people [who] need that from you, you want to help them once you get there [Somalia]."

Many of the mothers also explained that they were on their own pathways to higher education in Somalia until the civil war forced them to uproot their lives and end their own educational pursuits. Nimo explained,

My family pretty much they was educated. They finished

University of Somalia. . . . So my plan was to be like them, but

civil war happened. So I always tell my kid, "Don't miss what I

missed."

The mothers had a multi-layered desire to support their children in education: They came from educated families and the expectation of an education was intergenerationally transferred.

Furthermore, the mothers, who maintained their ties to their home country, understood that an 
Youth Aspirations in the Somali Diaspora

education would prepare their children to improve the lives of others in Somalia. Their children-at this early stage in their development-embraced these aspirations as their own.

\section{Changing Aspirations: "I'm undecided right now."}

In this section I highlight the changing aspirations of three youth: Khalid, Marwa, and Roodoo. These three young people were the only participants who were in high school during the study. At the beginning of the study, they were all beginning their freshman year. As the study concluded, they were finishing their first year as high school students-a time that aligned with a transition to middle adolescence. In their first interviews at the beginning of the school year, Khalid, Marwa, and Roodoo each expressed a desire to become a doctor. By the end of their first year of high school, they all had abandoned their initial career aspiration that closely matched their parents' aspirations for them, and instead described aspirations to explore diverse interests and pursue individual happiness. For instance, Khalid, an A student and Nimo's son, initially wanted to be a doctor because his aunt and mother encouraged it. At the end of his first year of high school he said, "I'm undecided right now" about his future. He explained that in high school, he had been "exposed to so many environments like taking some math classes, some business." He had begun to explore individual interests he discovered in school.

Prior to beginning her ninth-grade school year, Marwa-also a straight-A student and Fatima's daughter-expressed an aspiration to be a doctor, tying it to the value of helping others, telling me "that's what the world is about." By the end of her ninth grade year, she said she was undecided on her future and was looking forward to being able to "branch out" in her learning. One way she planned to do this was to take elective coursework, like film and media studies. In Marwa's case, by the end of her freshman year, she had moved away from her aspirations of being a doctor so that she could "help others," and instead had a more open-ended and individualized aspiration for her future explaining, "I just want to do something that makes me happy in the long run."

Finally, Roodoo, also in ninth grade, initially stated she wanted to become a surgeon or a veterinarian because she wanted to make her "parents proud." Throughout the year, she admitted she had a hard time living up to her parents' expectations of being "good" and struggled to earn good grades. She also participated in what her parents referred to as "games" that distracted her from her school work. She played on the school basketball team when permitted by her parents. Roodoo also loved drawing and make-up, and spent time at program sketching and looking up make-up tutorials on YouTube. By the end of her ninth-grade year, 
Roodoo was uncertain of her career path, but said she wanted to move to California for college explaining that it is because "it's where people find themselves. It's like I'm going to be free and I get to do whatever I want"-emphasizing her individual happiness and not her parents' at this point in time. Roodoo's vision of her perfect future that she drew at the end of her ninth grade year (Figure 2) shows that she was imagining a future that included playing basketball, living in a state far from family, and having non-Somali friends-social arrangements her parents had discouraged. Like Marwa and Khalid, Roodoo's aspirations changed from embracing her parents' values to pursuing individual interests fostered in non-family social contexts (e.g. sports, her neighborhood, online).

\section{Figure 2. Roodoo's Perfect Future}

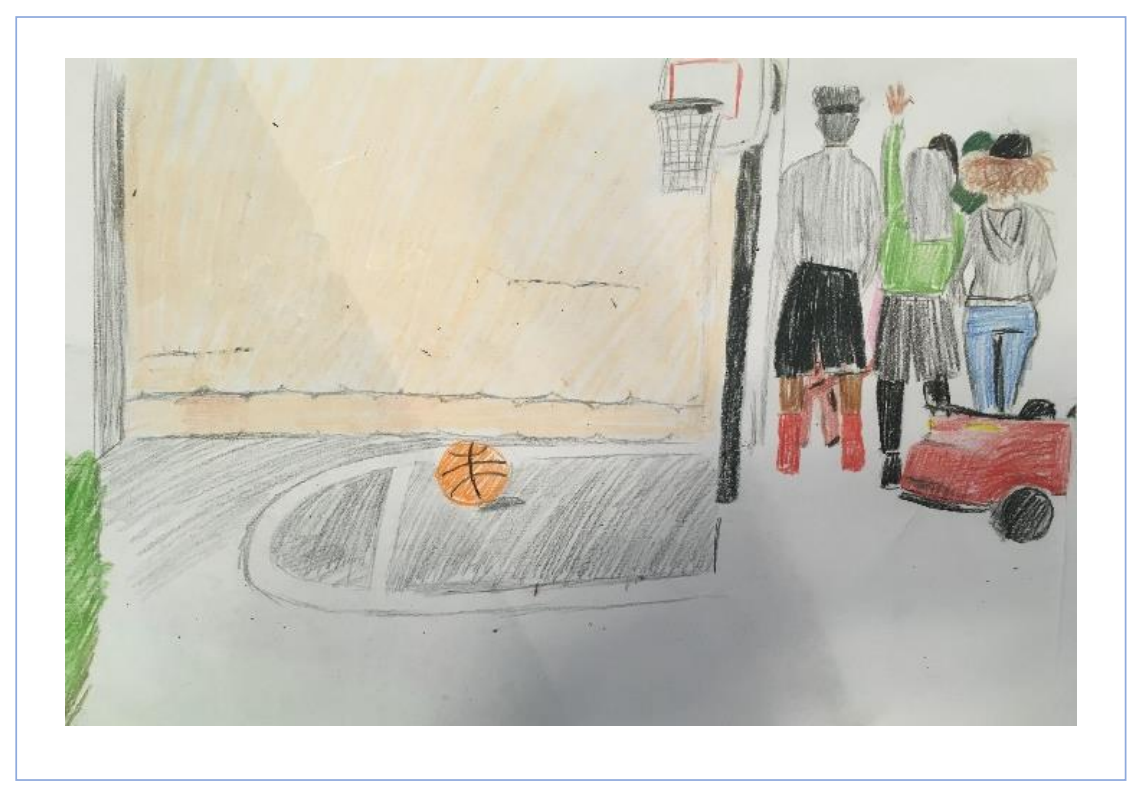

\section{Family Support:" Without parents, you can't do anything."}

These changed aspirations among the three older youth do not demonstrate youth willfully distancing themselves from their parents. Each of the young people, including the three high school students, maintained throughout the study that their parents (particularly their mothers) were their primary source of support. Many of the youth credited their parents' support for their education as the reason they held aspirations for their future. Hodan simply described that "without parents, you can't do anything," explaining that her mother strengthened her ability to dream. Layla (Khalid's sister; Nimo's daughter) explained why she believed her parents supported her and her siblings so much: "In Somalia they didn't have the opportunities that we 
Youth Aspirations in the Somali Diaspora

have right now and they encourage us to . . . actually go for the gold." Youth had cited parental support in their education-support which was seemingly amplified by their parents' experiences as refugees - but the older youths' evolving aspirations demonstrate a misalignment between the families' dispositions toward education (education for the benefit of others) and the dominant culture's disposition (education as a way to pursue individual interests). Young people were presented with the tension of reconciling these two discrepant values systems along their educational pathways, while retaining their family's support. This misalignment of value systems must be considered and addressed in order to support youths' abilities to exercise their capacity to aspire (Appadurai, 2004).

\section{Discussion}

Youth departing from the protection of their family and working toward interdependence with peers and other adults epitomizes adolescent development (Hirsch, 2005). This study offers a new context in which to understand this process: the Minnesota Somali diaspora. The changed aspirations of the three older youth do not necessarily demonstrate an intellectual shift in academic interests, but instead signal the youths' evolving engagement in their multiple social contexts during their development. Assessing the adolescent development of youth in this new context highlights the cultural discrepancies around education that youth navigate in their everyday developmental interactions as they strive to achieve their aspirations.

These findings also offer conceptual implications about the field's understanding of aspirations and the role they play in helping young people thrive in the future through education. The findings demonstrate that context matters and support the postulation that culture can by a catalyst for positive change (Appadurai, 2004; DeJaeghere, 2018). All youth, at one point in time, cited their cultural ties to the country of Somalia, their parents' refugee experiences, and the values their parents instilled in them as the reason why they held educational aspirations. Family-meditated cultural values enabled youth to aspire. Yet, the pathways to achieving their aspirations, vis à vis youth agency, became murkier as youth more deeply engaged with peers and teachers at school-a social context with different cultural values. They began to embrace the values of American individualism, values that other studies suggest Somali parents aimed to resist so as not to distance their children from their Somali cultural identity (e.g. Bigelow, 2010). Grounding these empirical findings in this conceptual understanding of youth aspirations suggests that in a school setting, youth in the Somali diaspora are encouraged to pursue aspirations rooted in individual interests, talents, and prosperity, but in a family setting, they are encouraged to pursue a career that contributes to the social good in their parents' home 
Youth Aspirations in the Somali Diaspora

country. This study took the first step to reconciling these discrepancies by bringing to light the different (and arguably competing) cultural logics informing youths' aspirations for their future. This study also lays the foundation for future research to understand the ways in which youth in the Somali diaspora must navigate multiple social contexts on their pathways to educational aspiration achievement.

\section{Implications for Practice}

These findings surface three ways to support the educational aspirations of youth and families in the Somali diaspora.

There Is a Need to Create Spaces for Young People to Reflect on and Voice Their Aspirations. There is a need to for Somali diasporic youth to have a place to imagine and reimagine their futures with adults and peers who allow them to change their minds and even contradict themselves. Aspirations are not a linear process from present to future; but instead are dynamic, socially and culturally constructed, and likely to change as youth develop and engage in new social environments (Conradie \& Robeyns, 2013; DeJaeghere 2018). Discussions, mentoring, and hands-on learning experiences around the topic of aspirations that span a period of time give youth opportunities to maintain an orientation toward the future throughout their development and create the conditions for the "birth of new aspirations" or the "discovery of latent aspirations" (Conradie \& Robeyns, 2013, p. 562). This is especially important for youth in the Somali diaspora who are trying to reconcile discrepant value systems that have the potential to disrupt their future orientation (or abilities to achieve their aspirations) if not explored in safe places.

\section{There Is a Need for Young People to Explore Interests Relevant to Their Lives.}

In this study, Somali diasporic youths' aspirations were connected to living out family values as well as to youths' desires to assert their independence. DeJaeghere (2018) found in her research of girls' aspirations in a low-resourced Tanzanian community, that "focus on content knowledge and exams overshadows important discussions about how the subject knowledge relates to a young person's life" (p. 252). Since aspirations are informed by social identities, youth must find ways to connect who they want to become to the multiple identities they hold in the present-not just based on content knowledge related to their cited career aspiration. 
Youth Aspirations in the Somali Diaspora

There Is a Need to Rethink Youth Development Measures That Focus on Individual DecisionMaking.

This study, like the work of DeJaeghere (2018) and Zipin et al (2015), builds on Appadurai's claim that aspirations are socially and culturally constructed ways of being and thinking of the future. Youths' cultural ties to Somalia, as mediated by their parents, fostered their capacities to aspire. If young people in the Somalia diaspora made only self-interested, individualized decisions toward their future thriving, they would risk distancing themselves from the values and cultural ways of being of their families, the people they cite as their strongest support systems. There is a need to allow young people to explore interests and exercise their cultural capacities to aspire in ways that will not require them to distance themselves from their families (Appadurai, 2004).

\section{Limitations and Delimitations}

This study was an exploration of the educational aspirations of young people and their families in the Minnesota Somali diaspora at a particular moment in time in their adolescence. Their aspirations will likely continue to change and evolve. Research that sticks with youth through multiples stages of development would be helpful in order to understand how to continue to support youth in the Minnesota Somali diaspora.

Because this was a narrowly defined target group and this study did not involve an experimental design, the findings from this study were not intended to be generalizable to a larger population. Rather, this study explored youth aspirations in a specific context so that it could illuminate larger lessons regarding how youth in the Somali diaspora imagined their future aspirations within social, cultural, and temporal contexts.

\section{References}

Abdi, N. M. (2015). Race, and religion in the making of Somali youth identities (Doctoral dissertation). Retrieved from Dissertations \& Theses @ CIC Institutions; ProQuest Dissertations \& Theses A\&I. (1749792877).

Appadurai, A. (2004). The capacity to aspire. In V. Rao \& M. Walton (Eds.), Culture and public action (pp. 59-84). Stanford, CA: Stanford University Press.

Bankston, C. L., III, \& Zhou, M. (2002). Social capital and immigrant children's achievement. In B. Fuller \& E. Hannum (Eds.), Schooling and social capital in diverse cultures (pp. 1-12). Amsterdam, Netherlands: Elsevier Science Ltd. 
Journal of Youth Development | http://jyd.pitt.edu/ | Vol. 14 Issue 2 DOI 10.5195/jyd.2019.717

Youth Aspirations in the Somali Diaspora

Basford, L. E. (2008). From mainstream to East African charter: East African Muslim students' experiences in U.S. schools (Doctoral dissertation) Retrieved from Dissertations \& Theses @ CIC Institutions; ProQuest Dissertations \& Theses A\&I. (304581839).

Bigelow, M. H. (2010). Mogadishu on the Mississippi: Language, racialized identity, and education in a new land. Maldon, MA: John Wiley \& Sons.

Bok, J. (2010). The capacity to aspire to higher education: 'It's like making them do a play without a script'. Critical Studies in Education, 51(2), 163-178. doi:10.1080/17508481003731042

Bourdieu, P. (1990). Outline of a theory of practice. Cambridge, UK: Cambridge University Press.

Bourdieu, P., \& Passeron, J. C. (1990). Reproduction in education, society, and culture. Beverly Hills, CA: Sage.

Conradie, I., \& Robeyns, I. (2013). Aspirations and human development interventions. Journal of Human Development and Capabilities, 14(4), 559-580. doi:10.1080/19452829.2013.827637

DeJaeghere, J. (2018). Girls' educational aspirations and agency: imagining alternative futures through schooling in a low-resourced Tanzanian community. Critical Studies in Education, 59(2), 237-255. doi:10.1080/17508487.2016.1188835

Duckworth, A. (2016). Grit: The Power of Passion and Perseverance. London, UK: Ebury.

Futch, V. A., \& Fine, M. (2014). Mapping as a method: History and theoretical commitments. Qualitative research in psychology, 11(1), 42-59. doi:10.1080/14780887.2012.719070

Hirsch, B. (2005). A place to call home: After school programs for urban youth. New York, NY: Teachers College Press.

Hurtado, G. A., Fife, J. M., Svetaz, M. V., \& Allen, M. L. (2018). Assessing multicultural parenting values and practices in prevention programs for Latino youth. Journal of Youth Development, 13(3), 6175. doi:10.5195/jyd.2018.615

Hussein, F. (2012). Charter schools: Choice of Somali-American parents? Bildhaan: An International Journal of Somali Studies, 11(1), 16.

Kapteijns, L., \& Arman, A. (2008). Educating immigrant youth in the United States: An exploration of the Somali case. Bildhaan: An International Journal of Somali Studies, 4(1), 18-43.

Minnesota State Demographic Center. (2016). The economic status of Minnesotans: A chartbook with data for 17 cultural groups. Retrieved from https://mn.gov/admin/assets/the-economic-status-ofminnesotans-chartbook-msdc-jan2016-post_tcm36-219454.pdf

Minnesota Department of Education. (2016). Minnesota student survey reports 2013-2016. Retrieved from: http://w20.education.state.mn.us/MDEAnalytics/DataTopic.jsp?TOPICID =242

Morrow, V., \& Crivello, G. (2015). What is the value of qualitative longitudinal research with children and young people for international development? International Journal of Social Research Methodology, 18(3), 267-280. doi:10.1080/13645579.2015.1017903 
Prodonovich, S., Perry, L. B., \& Taggart, A. (2014). Developing conceptual understandings of the capacity to aspire for higher education. Issues in Educational Research, 24(2), 174-189.

Reay, D. (2004). Education and cultural capital: The implications of changing trends in education policies. Cultural Trends, 13(2), 73-86. doi:10.1080/0954896042000267161

Saldaña, J. (2003). Longitudinal qualitative research: Analyzing change through time. Lanham, MD: Altamira Press.

Stanton-Salazar, R. D. (2011). A social capital framework for the study of institutional agents and their role in the empowerment of low-status students and youth. Youth \& Society, 43(3), 1066-1109. doi:10.1177/0044118X10382877

TAYO Consulting Group. (2016). Pathways to dignity: A human security approach to uplift Minnesota's Somali youth. Retrieved from http://tayocg.com/resources/

Tzenis, J. (2018). Contradictions of belonging: The educational aspirations and agency of youth in the Somali diaspora (Doctoral dissertation). Retrieved from the University of Minnesota Digital Conservancy, http://hdl.handle.net/11299/200242

Yusuf, A. I. (2012). Somalis in Minnesota. St. Paul, MN: Minnesota Historical Society.

Zipin, L., Sellar, S., Brennan, M., \& Gale, T. (2015). Educating for futures in marginalized regions: A sociological framework for rethinking and researching aspirations. Educational Philosophy and Theory, 4オ(3), 227-246. doi:10.1080/00131857.2013.839376 